\title{
Endothelial nitric oxide synthase gene polymorphisms and diabetic nephropathy: A HuGE review and meta-analysis
}

\author{
Elias Zintzaras, $M S c$, $P h D^{1,2}$, Afroditi A. Papathanasiou, $P h D^{I}$, and Ioannis Stefanidis, $M D^{3}$
}

\begin{abstract}
Candidate-gene association studies that examined the association between polymorphisms of endothelial nitric oxide synthase (NOS3) gene (G894T, 4b/a, and T786C) and diabetic nephropathy or diabetes leading to severe nephropathy produced inconclusive results. Thus, a meta-analysis of all candidate-gene association studies with endothelial nitric oxide synthase genotyping (7401 cases and 8046 controls) was conducted. Other study designs, such as family-based association studies and genome-wide linkage and association studies were also reviewed for supportive evidence of implication of endothelial nitric oxide synthase gene in diabetic nephropathy. The meta-analysis showed that G894T is significantly associated with diabetic nephropathy and diabetes leading to severe nephropathy in type 2 diabetics and in East Asians, respectively. Concerning the $4 \mathrm{~b} / \mathrm{a}$ polymorphism and its relationship to diabetes leading to severe nephropathy, a significant association was shown for East Asians. Heterogeneity between studies was in general high. There was no differential magnitude of effect in large versus small studies. One genome-wide linkage scan provided evidence of linkage nearby the endothelial nitric oxide synthase locus. Studies exploring gene and environment interactions with endothelial nitric oxide synthase polymorphisms may help understand better the genetics of diabetic nephropathy. Genet Med 2009:11(10):695-706.
\end{abstract}

Key Words: eNOS, NOS3, G894T, 4b/a, T786C, diabetic nephropathy, diabetes, polymorphism, meta-analysis, genetic epidemiology

\section{Gene and gene variants}

Vascular endothelial nitric oxide (NO) regulates endothelial function and precipitates vasodilatory effects in multiple organs, including the kidney. ${ }^{1} \mathrm{NO}$ is produced by the oxidation of L-arginine to L-citrulline by NO synthase (NOS). There are three isoforms of NOS: endothelial NOS (eNOS), neuronal NOS, and inducible NOS. ${ }^{2,3}$ Each isoform is coded by separate genes with a different pattern of expression. ${ }^{4}$ The $e N O S$ gene (NOS3) is located on chromosome 7q35-36, and it comprises 26 exons and 25 introns, with an entire length of $21 \mathrm{~kb} .{ }^{4}$ Variants of eNOS gene contribute to endothelial dysfunction and attenuate the NO production. ${ }^{5}$ Dysfunctional eNOS may play a critical role in the pathogenetic pathway, leading to diabetic vascular

From the ${ }^{1}$ Department of Biomathematics, University of Thessaly School of Medicine, Larissa, Greece; ${ }^{2}$ Center for Clinical Evidence Synthesis, Institute for Clinical Research and Health Policy Studies, Tufts Medical Center, Tufts University School of Medicine, Boston, Massachusetts; and ${ }^{3}$ Department of Nephrology, Larissa University Hospital, University of Thessaly School of Medicine, Larissa, Greece.

Elias Zintzaras, MSc, PhD, Department of Biomathematics, University of Thessaly School of Medicine, Papakyriazi 22, Larissa, 41222 Greece. E-mail: zintzara@med.uth.gr.

Disclosure: The authors declare no conflict of interest

Submitted for publication December 9, 2008.

Accepted for publication June 8, 2009.

Published online ahead of print September 19, 2009.

DOI: $10.1097 /$ GIM.0b013e3181b2046b complications including diabetic nephropathy (DN). ${ }^{6}$ Several polymorphisms of the eNOS gene have been identified, and their association with various diseases has been investigated, including coronary artery disease, myocardial infarction, coronary spasm, hypertension, end-stage renal disease (ESRD), and DN. ${ }^{4,7-10}$ The most clinically relevant polymorphisms that have been described in the eNOS gene ${ }^{11}$ are the following: (i) a G894T substitution in exon 7 that results in a Glu to Asp substitution at codon $298,{ }^{7}$ (ii) an insertion-deletion in intron 4 consisting of two alleles (the a-deletion has 4 tandem 27-bp repeats, and the b-insertion has 5 repeats), ${ }^{12}$ and (iii) a T786C substitution in the promoter region, which is strongly linked to 4b/a. The allele C of T786C polymorphism decreases promoter activity to less than half of normal activity, influencing thereby the progression of renal disease. . $^{8,13}$ Recent findings have implicated these polymorphisms of eNOS gene in DN. ${ }^{5}$

\section{Disease}

$\mathrm{DN}$ is a chronic microangiopathic complication of both type 1 (T1DM) and type 2 diabetes mellitus (T2DM) and is the primary cause of ESRD. ${ }^{14}$ The syndrome is typically observed in patients with diabetes duration of $>15$ years. The disease has higher prevalence in men and is characterized by a progressive clinical course, ultimately leading to death. The typical clinical course includes the following consecutive stages ${ }^{15}$ : microalbuminuria, macroalbuminuria (or proteinuria), and chronic renal failure, which ends up in ESRD. Existence of microalbuminuria is very frequently not accompanied by any histological lesions in the glomeruli, and it may even be reversible in a considerable number of cases. Therefore, overt DN is strictly defined based on the existence of proteinuria and/or renal failure. ${ }^{16}$ The risk for $\mathrm{DN}$ is greater when blood glucose is poorly controlled. However, the development of DN cannot be predicted only from glycemic control: $30 \%$ of diabetics ever develop DN, even if blood glucose control is excellent. ${ }^{17}$ Complications of chronic renal failure are more likely to occur earlier and progress more rapidly when the cause of renal failure is diabetes. Even after initiation of dialysis or after transplantation, patients with diabetes tend to do worse than those without diabetes. However, the etiology of DN is multifactorial and involves both environmental and genetic factors. ${ }^{18} \mathrm{~A}$ familial clustering of $\mathrm{DN}$ indicated that a genetic predisposition is implicated in the pathogenesis of DN in both types of diabetes. ${ }^{19-23}$ Nevertheless, the genetic component of the pathophysiologic process of DN has not yet been deciphered. ${ }^{24}$ Because numerous genetic and environmental factors, along with their interactions, are considered to be implicated in the pathogenesis of DN, polymorphisms of individual genes are expected to confer a modest risk to susceptibility of DN.

Genetic association studies that examined whether variants in eNOS gene are associated with $\mathrm{DN}$ or with diabetes leading to severe nephropathy (DSN) have yielded conflicting or inconclusive results. The lack of replication might be due to small sample sizes, different populations, sampling strategies, genotyping procedures, and number of loci included in the studies. ${ }^{25}$ 
To shed some light on these controversial results and to provide better power to detect smaller effect sizes, a comprehensive meta-analysis of all available candidate-gene population-based association studies relating variants of the $e N O S$ gene to the risk of developing DN, or DSN, was performed. ${ }^{25,26}$ In the metaanalysis, a spectrum of genetic contrasts was explored. In addition, the heterogeneity between studies and the existence of potential bias were investigated. ${ }^{25,27}$ Cumulative meta-analysis were also performed. ${ }^{25,28}$ Other study designs such as familybased association studies and genome-wide linkage and association studies were also reviewed for evidence that supports implication of eNOS gene in DN.

\section{METHODS}

\section{Identification and eligibility of relevant studies}

Candidate-gene case-control studies that determined the genotype distribution of G894T, 4b/a, and T786C polymorphisms in cases with diabetes and nephropathy, and (i) in diseased controls (subjects with diabetes and free of $\mathrm{DN}$ ) or (ii) in healthy controls, were eligible for inclusion in the metaanalysis. The former showed association with DN and the latter showed association with DSN. Cases with diabetes were considered as suffering from DN on the basis of a persistent albuminuria (i.e., macroalbuminuria, equivalent to an overt glomerular proteinuria) or a persistent microalbuminuria with or without chronic renal insufficiency and in the absence of nondiabetic renal disease or patients with ESRD or renal transplantation. Cases groups consisting exclusively of subjects with microalbuminuria were excluded from the meta-analysis. The diseased control group consisted of subjects with diabetes and free of diabetic kidney disease, i.e., normoalbuminuria and normal renal function. Only studies in human subjects that used validated genotyping methods were considered. ${ }^{29}$ Case reports, editorials, and review articles were also excluded. In studies with overlapping cases or controls, the most recent and/or the largest in size study with extractable data were included in the metaanalysis. Family-based association studies, genome-wide linkage scans, and genome-wide association studies were included in the search for additional evidence implicating the eNOS gene in the pathogenesis of DN.

We searched PubMed (until December 2008) for English language articles using the following search criteria: gene or polymorphism, eNOS or endothelial nitric oxide synthase or nitric oxide synthase) and diabetic nephropathy or nephropathy or ESRD. The retrieved studies were then read in their entirety to assess their appropriateness for inclusion in the meta-analysis. All references cited in the studies were also reviewed to identify additional published work not indexed by the PubMed database.

\section{Data extraction}

From each study, the following information was abstracted: first author, journal, year of publication, ethnicity of the study population, demographics, clinical characteristics, matching, validity of the genotyping method, and the number of cases and controls for each G894T, 4b/a, and T786C genotypes. The frequencies of the alleles and the genotypic distributions were extracted or calculated, for both the cases and the controls. In addition, it was recorded whether the genotyping in each study was performed blinded to clinical status. When studies investigated more than one polymorphism, information on linkage disequilibrium (LD) and haplotype estimation (or combined genotypes) was recorded.

\section{Data synthesis and analysis}

The meta-analysis examined the association between each polymorphism and the risk of DN, or the risk of DSN, for the: (i) allele contrast, (ii) recessive, (iii) dominant, and (iv) additive models. ${ }^{24,30,31}$ The associations were indicated as a pooled odds ratio $(\mathrm{OR})$ with the corresponding $95 \%$ confidence interval (CI).

The heterogeneity between studies was tested using the Qstatistic. ${ }^{32}$ If $P_{\mathrm{Q}}<0.10$, then heterogeneity was considered statistically significant. Heterogeneity was quantified with the $I^{2}$ metric, which is independent of the number of studies in the meta-analysis. $I^{2}$ takes values between 0 and $100 \%$, with higher values denoting greater degree of heterogeneity. ${ }^{33}$ The pooled OR was estimated using random effects (RE) models. ${ }^{34} \mathrm{RE}$ modeling assumes a genuine diversity in the results of various studies, and it incorporates to the calculations a between-study variance. When there is lack of heterogeneity, the RE model coincides with the fixed effects model. ${ }^{25}$

A cumulative meta-analysis was performed to evaluate the trend of OR in time. ${ }^{25,28}$ In cumulative meta-analysis, studies were chronologically ordered by publication year, then the pooled ORs were obtained at the end of each year, i.e., at each information step. Cumulative meta-analysis provides a frame work for updating a genetic effect from all studies as evidence accumulates. $^{25}$ The cumulative meta-analysis was performed for the allele contrast of polymorphisms investigated in more than five information steps. A differential magnitude of effect in large versus small studies ${ }^{25}$ for the allele contrast of the most commonly studied polymorphism $(4 \mathrm{a} / \mathrm{b})$ was checked using the test proposed by Harbord et al. ${ }^{35}$

The meta-analysis consisted of the main (overall) analysis, which includes all available data, subgroup analyses by race (or ethnicity), and diabetes type. A sensitivity analysis, which examines the effect of excluding specific studies, was also performed. ${ }^{25}$ The distribution of the genotypes in the healthy control group was tested whether it is in Hardy-Weinberg equilibrium (HWE) using an exact test. ${ }^{36}$ The meta-analysis was subjected to sensitivity analysis for studies with the controls not in HWE. ${ }^{37}$ Analyses were performed using Meta-Analyst (Joseph Lau, Boston, MA, 1998), and Compaq Visual Fortran 90 (International Mathematics and Statistics Library).

\section{RESULTS}

\section{Eligible studies and study characteristics}

The literature review identified 92 titles in PubMed. The full articles of the retrieved studies were read to assess their appropriateness for meta-analysis according to the inclusion criteria. Data from 20 articles that investigated the association between any of the G894T, $4 \mathrm{a} / \mathrm{b}$, and T786C polymorphisms and DN or DSN met the inclusion criteria, and they were included in the meta-analysis. ${ }^{2-6,13,38-51}$ Two articles involved only patients with microalbuminuria, and therefore these articles were excluded. ${ }^{52,53}$ The genotype distribution of one study ${ }^{54}$ was identical with the one in Nagase et al., ${ }^{44}$ and in one study, ${ }^{55}$ the subjects overlapped with the subjects of the study by Buraczynska et al. ${ }^{43}$ Figure 1 presents a flowchart of retrieved studies and studies excluded, with specification of reasons. The studies were published between 1999 and 2008

A list of details abstracted from the studies included in the meta-analysis is provided in Table 1. Four articles investigated association with both DN and DSN. Thus, data were obtained from 24 studies. In investigating association with DN, 5 studies dealt with G894T, 10 with 4b/a, and 3 with T786C. For DSN, five studies dealt with G894T, nine with 4b/a, and two with 


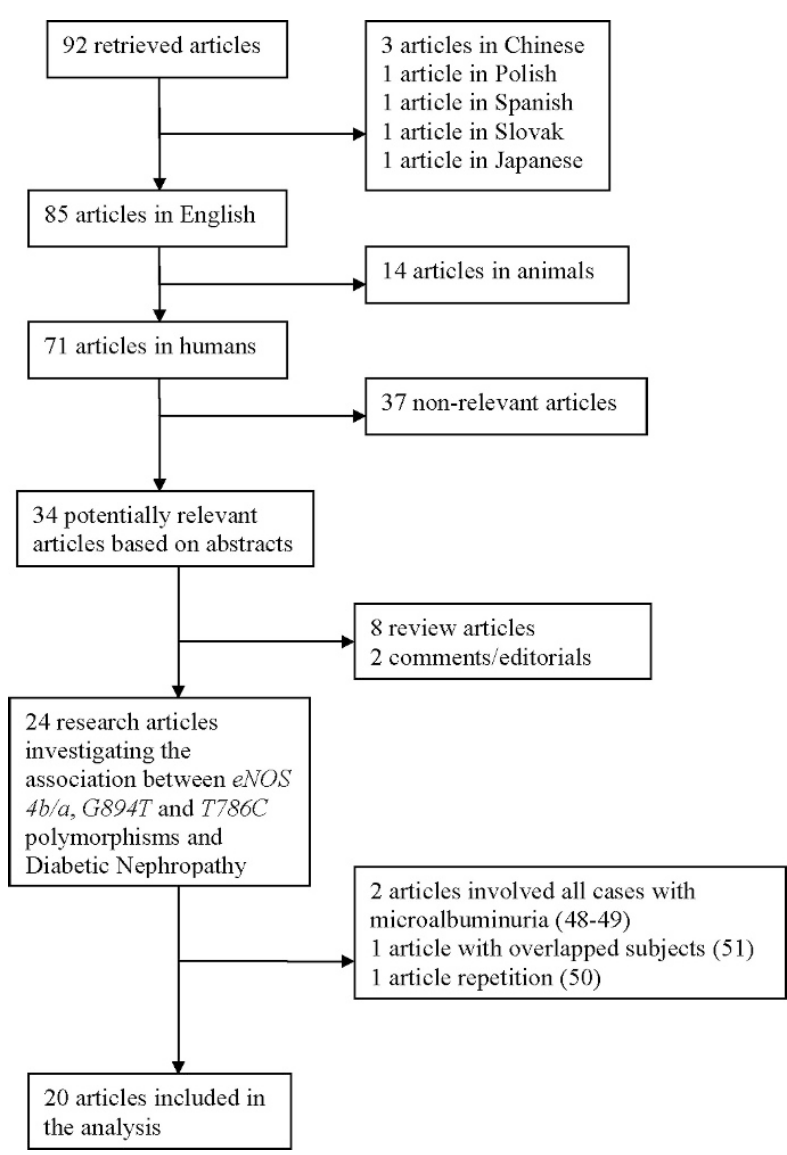

Fig. 1. Flowchart of retrieved studies and studies excluded, with specification of reasons.

T786C. Three studies investigated the three polymorphisms together and two studies two polymorphisms (G894T and 4a/b). In all studies, valid genotyping methods were used: polymerase chain reaction (PCR) and restriction of the PCR product with the corresponding enzyme or PCR with allele specific probes (G894T and T786C), and electrophoretic differentiation (4b/a). Thirteen studies involved cases with T2DM and three with T1DM. The remaining studies did not specify the diabetes type, and all of them investigated DSN. Nine studies on DSN concerned patients with ESRD, and one study involved cases with microalbuminuria (18\% of cases). ${ }^{40}$ Three studies in DN, and one study in DSN, stated that the controls were gender and sex matched. Studies were conducted in various populations of racial descent: 5 involved whites, 14 East Asians, and 5 other ethnicities (Asian Indians, Arabs, and mixed). Data were extracted by the two authors, and disagreements were resolved after discussion.

The search criteria and the review of the cited references also identified 2 family-based association studies for eNOS in DN, 4,56 12 genome-wide linkage scans, ${ }^{57-68}$ and 3 genome-wide association studies ${ }^{69-71}$ (two of them were overlapping, ${ }^{70,71}$ and consequently, only the most recent one was evaluated ${ }^{70}$ ).

\section{Summary statistics}

The studies in DN provided 1942/1461 cases/controls for G894T, 2663/2232 cases/controls for 4b/a, and 857/845 cases/controls for T786C. One study 4 provided data only for the allele frequencies. The frequency (\%) of alleles 894T, 4b, and $\mathrm{T} 786 \mathrm{C}$ in cases/controls were $33.8 / 30.7,17.0 / 15.5$, and $28.8 / 25.8$, respectively.

The studies in DSN provided 755/1541 cases/controls for G894T, 674/1231 cases/controls for 4b/a, and 510/736 for T786C. One study 3 provided data only for the $894 \mathrm{~T}$ carriers. The frequency (\%) of alleles $894 \mathrm{~T}, 4 \mathrm{~b}$, and T786C in cases/ controls were $34.8 / 21.7,18.0 / 13.4$, and $25.8 / 19.7$, respectively. The frequency of the risk allele for each individual study polymorphism for cases and controls is given in Table 1.

In one study, ${ }^{44}$ the distribution of the genotypes in control group was not in HWE $(P<0.05)$, indicating genotyping errors and/or population stratification ${ }^{25}$; therefore, a sensitivity analysis was performed excluding this study. Three studies provided analyses of eNOS haplotypes. ${ }^{4-6}$ One study ${ }^{6}$ reported lack of significant LD among the three studied polymorphisms.

\section{Main results, subgroup, and sensitivity analyses}

Table 2 shows the meta-analysis results for both DN and DSN for each polymorphism. Figure $2, a-c$ shows the results for the association between the different polymorphisms and the risk of DN, and Figure 3, a and b shows the results for DSN. We now analyze and further discuss the significant findings for each polymorphism in turn.

Overall, for the G894T polymorphism and its relationship to $\mathrm{DN}$, only the allele contrast ( $\mathrm{T}$ versus $\mathrm{G}$ ) showed a marginally significant association $(\mathrm{OR}=1.36,95 \% \mathrm{CI}: 1.02-1.81)$, and the heterogeneity between studies was significant $\left(P_{\mathrm{Q}}<0.01, I^{2}=\right.$ $83 \%$ ). In subgroup analysis for patients with T2DM, significant results were derived for all genetic contrasts except for the codominant model. The other subgroup analyses yielded nonsignificant results.

Regarding the relationship between the G894T polymorphism and the DSN, the heterogeneity between studies was significant $\left(P_{\mathrm{Q}}<0.01, I^{2}=83 \%\right)$, and the analysis detected an association for the allele contrast: $\mathrm{OR}=2.59,95 \% \mathrm{CI}: 1.37-$ 4.88. All remaining genetic contrasts also produced significant results. The results for T2DM were not consistent with the overall results; however, these results were based only on two studies and definitive conclusions cannot be drawn. In subgroup analysis for East Asians, the allele contrast showed significant association: $\mathrm{OR}=3.47,95 \% \mathrm{CI}: 2.35-5.12$. The dominant models, additive models, and codominant effects were also significant. The sensitivity analysis for HWE did not alter the pattern of results.

For the $4 \mathrm{~b} / \mathrm{a}$ polymorphism in DN, overall, the allele contrast showed significant heterogeneity between studies $\left(P_{\mathrm{O}}=0.04\right.$, $\left.I^{2}=48 \%\right)$, and the association was not significant $(\mathrm{OR}=1.14$, 95\% CI: 0.96-1.39). However, the recessive and additive models were marginally significant. In no other case were found any significant results.

Concerning the $4 \mathrm{~b} / \mathrm{a}$ polymorphism and its relationship to DSN, overall, the allele contrast showed heterogeneity between studies $\left(P_{\mathrm{Q}}<0.01, I^{2}=72 \%\right)$, and the association was significant $(\mathrm{OR}=1.56,95 \% \mathrm{CI}: 1.15-2.12)$. The rest genetic models also produced significant associations. In subgroup analysis, only East Asians showed significant associations for the recessive and additive models. The information provided for T2DM or whites was very limited, and the nonsignificant results produced for these subgroups should be interpreted with caution.

The overall analysis detected a marginal association between the T786C polymorphism and the risk of DN only for the allele contrast $(\mathrm{OR}=1.18,95 \% \mathrm{CI}: 1.01-1.37)$ and lack of heterogeneity $\left(P_{\mathrm{Q}}=0.73, I^{2}=0 \%\right)$. For DSN, a marginal significant association was only derived for the dominant model $(\mathrm{OR}=$ 


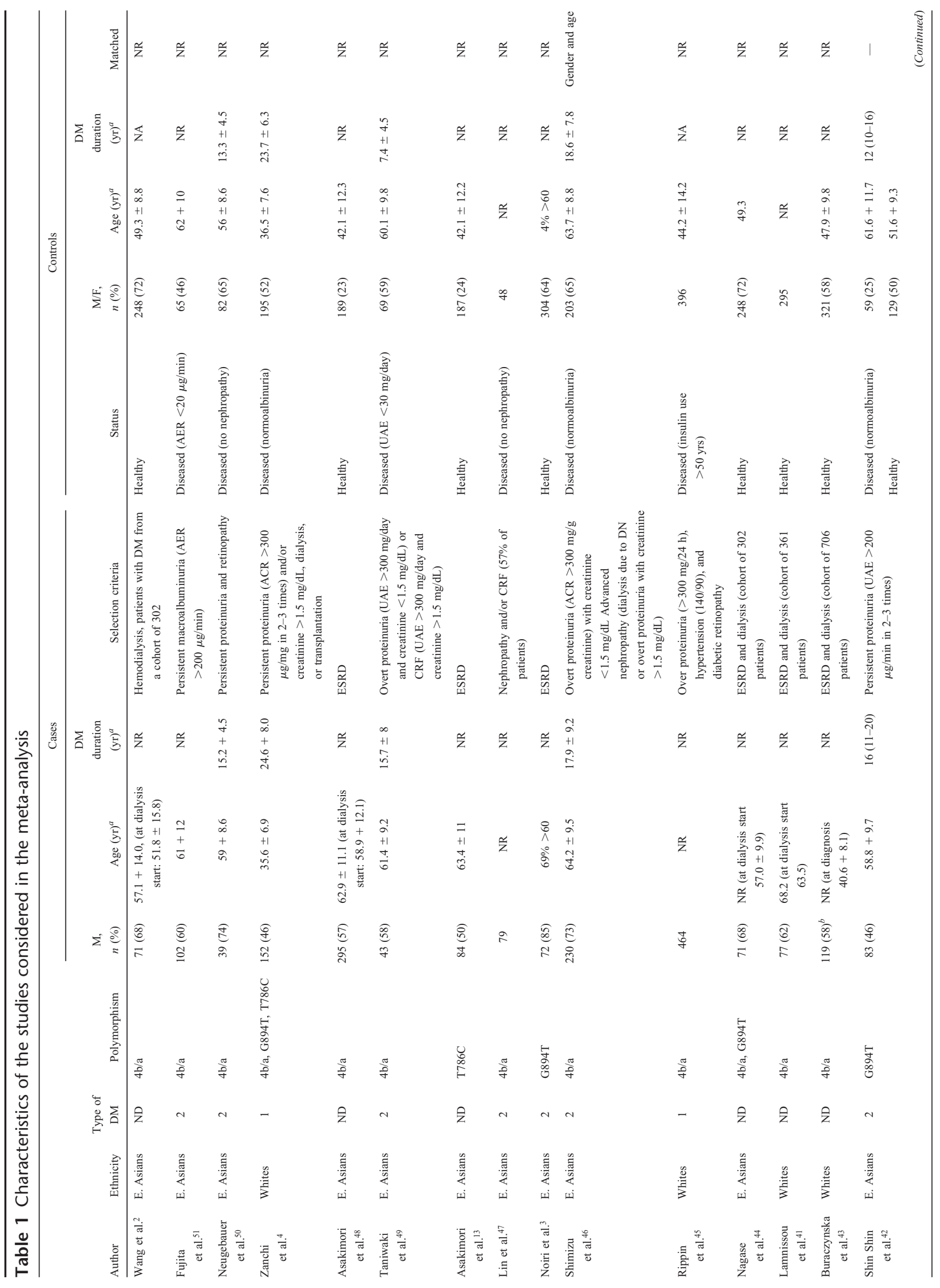




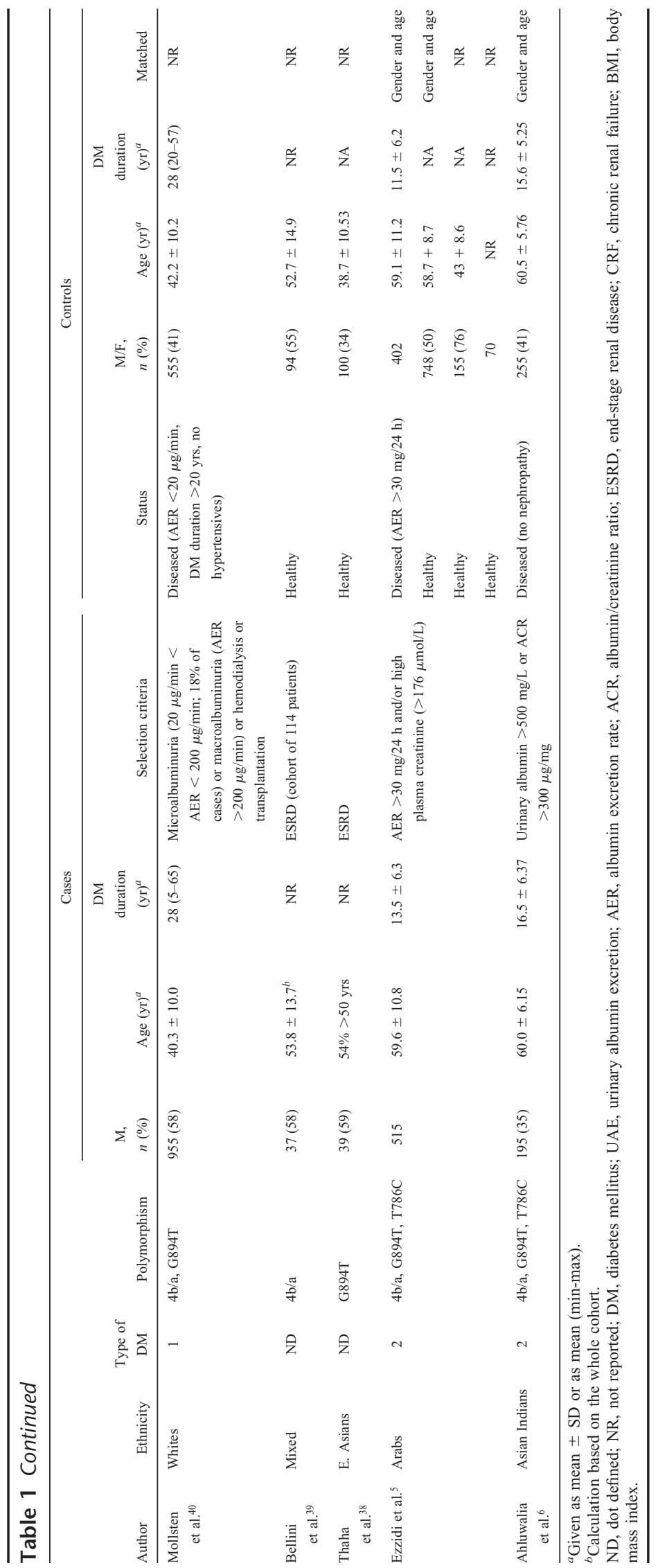


Table 2 Random effects odds ratios and heterogeneity results for the genetic contrasts of G894T, 4b/a, and T786C eNOS gene polymorphisms for diabetic nephropathy (DN) and diabetes (DM) leading to severe nephropathy (DSN)

\begin{tabular}{|c|c|c|c|c|c|}
\hline & Population & Studies & OR & $95 \% \mathrm{CI}$ & $I^{2}, \%\left(P_{\mathrm{Q}}\right)$ \\
\hline \multicolumn{6}{|l|}{ G894T } \\
\hline \multicolumn{6}{|l|}{ DN } \\
\hline \multirow[t]{4}{*}{ T vs. G } & All & 5 & 1.36 & $1.02-1.81$ & $83(<0.01)$ \\
\hline & DM type 1 & 2 & 1.32 & $0.64-2.72$ & $\mathrm{NA}(<0.01)$ \\
\hline & DM type 2 & 3 & 1.31 & $1.12-1.53$ & $0(0.41)$ \\
\hline & Whites & 2 & 1.32 & $0.64-2.72$ & $\mathrm{NA}(<0.01)$ \\
\hline \multirow[t]{2}{*}{ Recessive model } & All & 4 & 1.40 & $0.97-2.02$ & $54(0.12)$ \\
\hline & DM type 2 & 3 & 1.69 & $1.22-2.34$ & $0(0.88)$ \\
\hline \multirow[t]{2}{*}{ Dominant model } & All & 4 & 1.19 & $0.87-1.61$ & $67(0.03)$ \\
\hline & DM type 2 & 3 & 1.32 & $1.06-1.64$ & $3(0.36)$ \\
\hline \multirow[t]{2}{*}{ Additive model } & All & 4 & 1.44 & $0.90-2.30$ & $68(0.04)$ \\
\hline & DM type 2 & 3 & 1.81 & $1.28-2.57$ & $0(0.89)$ \\
\hline \multirow[t]{2}{*}{ Codominant } & All & 4 & 0.99 & $0.79-1.23$ & $42(0.16)$ \\
\hline & DM type 2 & 3 & 1.10 & $0.79-1.54$ & $46(0.16)$ \\
\hline \multicolumn{6}{|l|}{ DSN } \\
\hline \multirow[t]{4}{*}{ Allele contrast } & All & 4 & 2.59 & $1.37-4.88$ & $83(<0.01)$ \\
\hline & All in HWE & 3 & 2.41 & $1.14-5.09$ & $86(<0.01)$ \\
\hline & DM type 2 & 2 & 1.78 & $0.96-3.30$ & NA $(0.08)$ \\
\hline & East Asians & 3 & 3.47 & $2.35-5.12$ & $0(0.68)$ \\
\hline \multirow[t]{4}{*}{ Recessive model } & All & 5 & 1.87 & $1.34-2.61$ & $0(0.71)$ \\
\hline & All in HWE & 4 & 1.82 & $1.30-2.54$ & $0(0.97)$ \\
\hline & DM type 2 & 2 & 1.83 & $1.30-2.57$ & $0(0.91)$ \\
\hline & East Asians & 3 & 2.90 & $0.69-12.62$ & $0(0.79)$ \\
\hline \multirow[t]{4}{*}{ Dominant model } & All & 4 & 3.01 & $1.59-5.70$ & $87(<0.01)$ \\
\hline & All in HWE & 3 & 3.49 & $1.10-11.07$ & $90(<0.01)$ \\
\hline & DM type 2 & 2 & 1.92 & $0.97-3.79$ & NA $(0.08)$ \\
\hline & East Asians & 4 & 3.78 & $1.95-7.35$ & $67(0.06)$ \\
\hline \multirow[t]{4}{*}{ Additive model } & All & 4 & 2.24 & $1.57-3.20$ & $0(0.65)$ \\
\hline & All in HWE & 3 & 2.16 & $1.51-3.11$ & $0(0.79)$ \\
\hline & DM type 2 & 2 & 2.12 & $1.47-3.06$ & NA $(0.95)$ \\
\hline & East Asians & 3 & 5.11 & $1.20-21.82$ & $0(0.85)$ \\
\hline \multirow[t]{5}{*}{ Codominant } & All & 4 & 3.04 & $1.09-8.47$ & $90(<0.01)$ \\
\hline & All in HWE & 3 & 3.17 & $0.84-11.97$ & $93(<0.01)$ \\
\hline & DM type 2 & 2 & 1.72 & $0.66-4.50$ & NA $(0.01)$ \\
\hline & East Asians & 3 & 4.47 & $1.91-10.43$ & $67(0.05)$ \\
\hline & & & & & (Continued) \\
\hline
\end{tabular}


Table 2 Continued

\begin{tabular}{|c|c|c|c|c|c|}
\hline & Population & Studies & OR & $95 \% \mathrm{CI}$ & $I^{2}, \%\left(P_{\mathrm{Q}}\right)$ \\
\hline \multicolumn{6}{|l|}{$4 \mathrm{~b} / \mathrm{a}$} \\
\hline \multicolumn{6}{|l|}{$\mathrm{DN}$} \\
\hline \multirow[t]{5}{*}{ b vs. a } & All & 10 & 1.14 & $0.96-1.37$ & $48(0.04)$ \\
\hline & DM type 1 & 3 & 1.18 & $0.92-1.51$ & $58(0.09)$ \\
\hline & DM type 2 & 7 & 1.14 & $0.85-1.52$ & $51(0.06)$ \\
\hline & Caucasians & 3 & 1.18 & $0.92-1.51$ & $58(0.09)$ \\
\hline & East Asians & 5 & 1.23 & $0.71-2.11$ & $54(0.07)$ \\
\hline \multirow[t]{5}{*}{ Recessive model } & All & 10 & 1.68 & $1.07-2.66$ & $35(0.13)$ \\
\hline & DM type 1 & 3 & 1.32 & $0.85-2.05$ & $0(0.48)$ \\
\hline & DM type 2 & 7 & 2.09 & $0.88-4.95$ & $49(0.07)$ \\
\hline & Caucasians & 3 & 1.32 & $0.85-2.05$ & $0(0.48)$ \\
\hline & East Asians & 5 & 1.89 & $0.67-5.35$ & $0(0.54)$ \\
\hline \multirow[t]{5}{*}{ Dominant model } & All & 10 & 1.07 & $0.90-1.27$ & $33(0.14)$ \\
\hline & DM type 1 & 3 & 1.17 & $0.89-1.52$ & $52(0.12)$ \\
\hline & DM type 2 & 7 & 0.98 & $0.77-1.26$ & $22(0.26)$ \\
\hline & Caucasians & 3 & 1.17 & $0.89-1.52$ & $53(0.12)$ \\
\hline & East Asians & 5 & 1.18 & $0.71-1.97$ & $40(0.15)$ \\
\hline \multirow[t]{5}{*}{ Additive model } & All & 10 & 1.68 & $1.06-2.67$ & $35(0.13)$ \\
\hline & DM type 1 & 3 & 1.35 & $0.87-2.10$ & $0(0.37)$ \\
\hline & DM type 2 & 7 & 2.03 & $0.86-4.79$ & $48(0.07)$ \\
\hline & Caucasians & 3 & 1.35 & $0.87-2.10$ & $0(0.37)$ \\
\hline & East Asians & 5 & 1.93 & $0.68-5.47$ & $0(0.49)$ \\
\hline \multirow[t]{5}{*}{ Codominant model } & All & 10 & 0.97 & $0.80-1.18$ & $39(0.10)$ \\
\hline & DM type 1 & 3 & 1.09 & $0.88-1.35$ & $24(0.27)$ \\
\hline & DM type 2 & 7 & 0.85 & $0.64-1.13$ & $30(0.20)$ \\
\hline & Caucasians & 3 & 1.09 & $0.88-1.35$ & $24(0.27)$ \\
\hline & East Asians & 5 & 1.03 & $0.71-1.49$ & $5(0.38)$ \\
\hline \multicolumn{6}{|l|}{ DSN } \\
\hline \multirow[t]{4}{*}{ Allele contrast } & All & 9 & 1.56 & $1.15-2.12$ & $72(<0.01)$ \\
\hline & DM type 2 & 3 & 1.69 & $0.95-3.00$ & $61(9.08)$ \\
\hline & Caucasians & 2 & 1.57 & $0.49-5.02$ & $\mathrm{NA}(<0.01)$ \\
\hline & East Asians & 5 & 1.49 & $0.95-2.33$ & $55(0.06)$ \\
\hline \multirow[t]{4}{*}{ Recessive model } & All & 9 & 3.18 & $1.78-5.68$ & $19(0.27)$ \\
\hline & DM type 2 & 3 & 3.31 & $0.70-15.65$ & $36(0.21)$ \\
\hline & Caucasians & 2 & 3.44 & $0.43-27.7$ & $\mathrm{NA}(0.02)$ \\
\hline & East Asians & 5 & 5.40 & $1.15-25.26$ & $0(<0.70)$ \\
\hline \multirow[t]{5}{*}{ Dominant model } & All & 9 & 1.52 & $1.11-2.09$ & $65(<0.01)$ \\
\hline & DM type 2 & 3 & 1.50 & $0.99-2.25$ & $29(0.25)$ \\
\hline & Caucasians & 2 & 1.55 & $0.43-5.52$ & $\mathrm{NA}(<0.01)$ \\
\hline & East Asians & 5 & 1.44 & $0.96-2.17$ & $39(0.16)$ \\
\hline & & & & & (Continued) \\
\hline
\end{tabular}


Table 2 Continued

\begin{tabular}{|c|c|c|c|c|c|}
\hline & Population & Studies & OR & $95 \% \mathrm{CI}$ & $I^{2}, \%\left(P_{\mathrm{Q}}\right)$ \\
\hline \multirow[t]{4}{*}{ Additive model } & All & 9 & 3.76 & $1.85-7.66$ & $37(0.13)$ \\
\hline & DM type 2 & 3 & 3.63 & $0.71-18.60$ & $39(0.20)$ \\
\hline & Caucasians & 2 & 3.86 & $0.33-45.0$ & NA $(0.01)$ \\
\hline & East Asians & 5 & 5.76 & $1.23-26.99$ & $0(0.67)$ \\
\hline \multirow[t]{4}{*}{ Codominant model } & All & 9 & 1.30 & $1.04-1.64$ & $32(0.16)$ \\
\hline & DM type 2 & 3 & 1.20 & $0.95-1.50$ & $0(0.62)$ \\
\hline & Caucasians & 2 & 1.26 & $0.49-3.26$ & NA $(0.01)$ \\
\hline & East Asians & 5 & 1.36 & $1.00-1.85$ & $0(0.41)$ \\
\hline \multicolumn{6}{|l|}{$\mathrm{T} 786 \mathrm{C}$} \\
\hline \multicolumn{6}{|l|}{$\mathrm{DN}$} \\
\hline \multirow[t]{2}{*}{ T vs. C } & All & 3 & 1.18 & $1.01-1.37$ & $0(0.73)$ \\
\hline & DM type 2 & 2 & 1.15 & $0.97-1.38$ & NA $(0.50)$ \\
\hline \multirow[t]{2}{*}{ Recessive model } & All & 3 & 1.86 & $0.70-4.92$ & $82(<0.01)$ \\
\hline & DM type 2 & 2 & 1.93 & $0.29-12.64$ & NA $(0.01)$ \\
\hline \multirow[t]{2}{*}{ Dominant model } & All & 3 & 1.17 & $0.96-1.42$ & $0(0.76)$ \\
\hline & DM type 2 & 2 & 1.21 & $0.97-1.50$ & NA $(0.65)$ \\
\hline \multirow[t]{2}{*}{ Additive model } & All & 3 & 1.83 & $0.77-4.39$ & $75(0.02)$ \\
\hline & DM type 2 & 2 & 2.02 & $0.35-11.63$ & NA $(0.01)$ \\
\hline \multirow[t]{2}{*}{ Codominant model } & All & 3 & 0.98 & $0.66-1.44$ & $71(0.03)$ \\
\hline & DM type 2 & 2 & 1.13 & $0.77-1.67$ & NA $(0.10)$ \\
\hline \multicolumn{6}{|l|}{ DSN } \\
\hline Allele contrast & All & 2 & 1.50 & $0.99-2.29$ & NA $(0.14)$ \\
\hline Recessive model & All & 2 & 1.40 & $0.87-2.26$ & NA $(0.82)$ \\
\hline Dominant model & All & 2 & 1.63 & $1.03-2.55$ & NA (0.14) \\
\hline Additive model & All & 2 & 1.59 & $0.97-2.59$ & NA $(0.80)$ \\
\hline Codominant model & All & 2 & 1.59 & $0.94-2.69$ & NA $(0.10)$ \\
\hline
\end{tabular}

1.63, 95\% CI: 1.03-2.55). However, the results were based only on two studies; thus, inferences should be made with caution.

\section{Potential bias}

None of the studies included in the meta-analysis stated that genotyping was performed by genotyping personnel blinded to clinical status. For the allele contrast of G894T in DN, there is statistical difference between the OR of the first study ${ }^{4}$ versus the OR of the subsequent studies $(P=0.02)$. The pooled OR without the first study was $\mathrm{RE} \mathrm{OR}=1.20,95 \%$ CI: $0.93-1.55$.

Although cumulative meta-analysis for $4 \mathrm{~b} / \mathrm{a}$ polymorphism in DN indicated a downward trend of association in the whole studied period (2000-2008; Fig. 4), it is evident that this trend is attributed to the first three studies (published in 2000). When the data of the period 2002-2008 were considered separately, there was an upward trend in cumulative OR for this period (in 2002, OR $=0.92,95 \%$ CI: $0.63-1.34$; in 2003, OR $=1.00$, 95\% CI: $0.80-1.25$; in 2006, OR $=1.03,95 \%$ CI: $0.89-1.20$; and in $2008, \mathrm{OR}=1.03,95 \%$ CI: $0.91-1.15)$. For the recessive and additive models, exclusion of one study ${ }^{6}$ diminished the significance of the associations found, and the ORs were as follows: $\mathrm{OR}=1.29,95 \% \mathrm{CI}: 0.92-1.79$ and $\mathrm{OR}=1.28,95 \%$ CI: $0.92-1.79$, respectively. In both contrasts, there were statistical differences between the OR of the excluded study ${ }^{6}$ versus the OR of the remaining studies $(P=0.02$ and $P=0.03$, respectively). The test by Harbord et al. ${ }^{35}$ for $4 \mathrm{~b} / \mathrm{a}$ in $\mathrm{DN}$ indicated that there is no differential magnitude of effect in large versus small studies $(P=0.24)$.

However, for the $4 \mathrm{~b} / \mathrm{a}$ polymorphism in DSN, cumulative meta-analysis indicated a trend of association as information accumulates (Fig. 4). The test by Harbord et al. ${ }^{35}$ for $4 \mathrm{~b} / \mathrm{a}$ in DSN indicated that there is no differential magnitude of effect in large versus small studies $(P=0.75)$.

\section{Evidence from family-based and genome-wide study designs}

The two family-based association studies investigated different variants. The one study ${ }^{4}$ examined the $\mathrm{T} 786 \mathrm{C}$ and $4 \mathrm{~b} / \mathrm{a}$ 


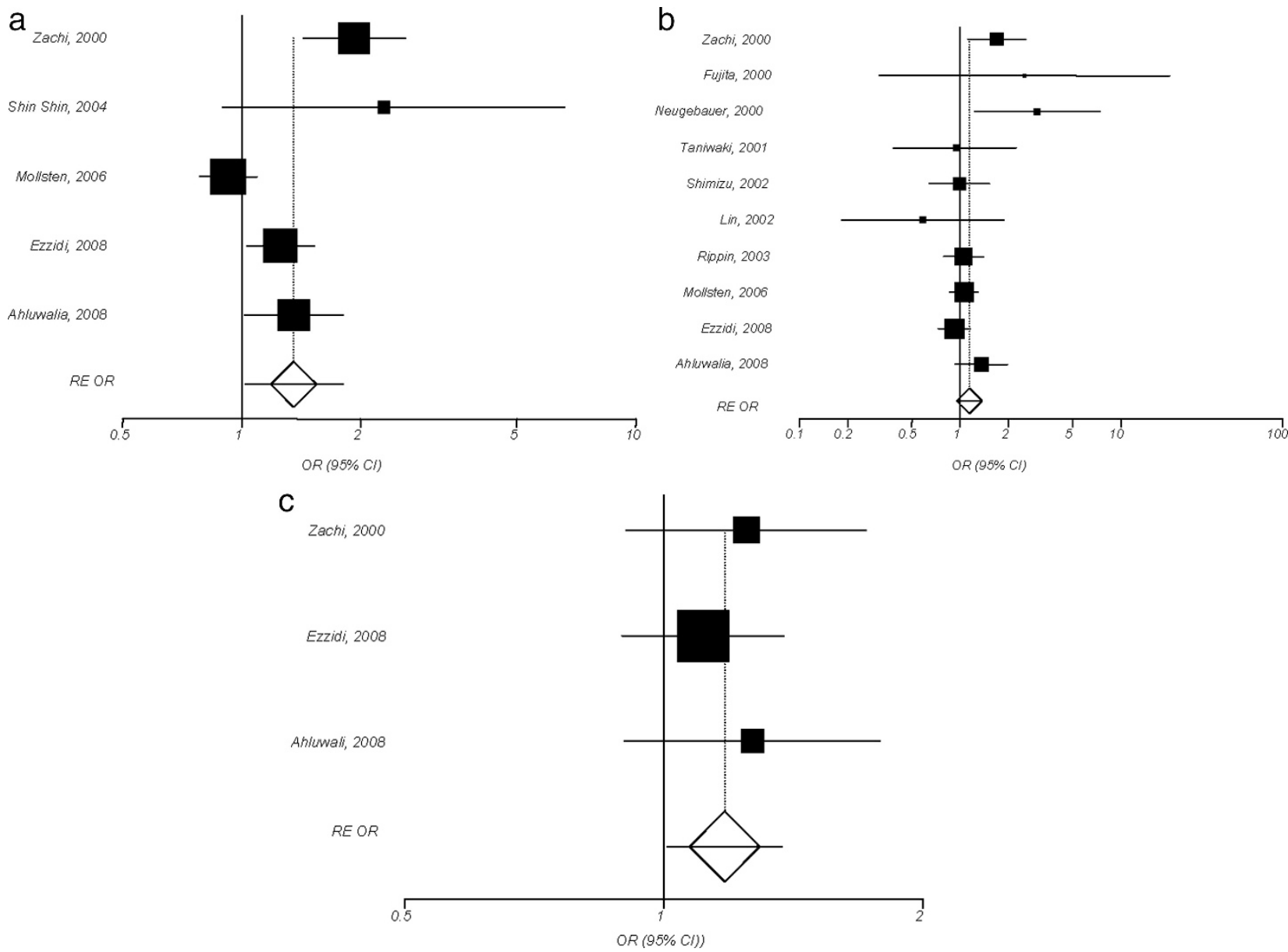

Fig. 2. Random effects (RE) odds ratio (OR) estimates with the corresponding $95 \%$ confidence interval $(\mathrm{Cl})$ for the allele contrast (a) G894T allele T, (b) 4b/a allele b, and (c) T786C allele T and the risk of DN. The OR estimate of each study is marked with a solid black square. The size of the square represents the weight that the corresponding study exerts in the meta-analysis. The Cls of pooled estimates are displayed as a horizontal line through the diamond; this line might be contained within the diamond if the $\mathrm{Cl}$ is narrow. The horizontal axis is plotted on a log scale.

polymorphisms and indicated no significant transmission from parents to offspring of $\mathrm{T}$ and $\mathrm{C}$ alleles of $\mathrm{T} 786 \mathrm{C}$ polymorphism in advance nephropathy and proteinuria $(\mathrm{OR}=1.41,95 \% \mathrm{CI}$ : $0.91-2.19$ and $\mathrm{OR}=0.87,95 \% \mathrm{CI}: 0.57-1.33$, respectively). For the $4 \mathrm{~b} / \mathrm{a}$ polymorphism, the transmission was significant for advanced nephropathy, but it was not for proteinuria $(\mathrm{OR}=$ 1.89, 95\% CI: $1.07-3.34$ and $\mathrm{OR}=1.04,95 \% \mathrm{CI}: 0.60-1.80$, respectively). The other study ${ }^{56}$ investigated four different variants of eNOS than those described earlier: C1067T, A26G, G894T, and A15G; none of these variants produced a significant transmission $(\mathrm{OR}=1.15,95 \% \mathrm{CI}: 0.63-2.09, \mathrm{OR}=1.08,95 \%$ CI: $0.63-1.84, \mathrm{OR}=1.10,95 \%$ CI: $0.61-1.98$, and $\mathrm{OR}=1.14$, 95\% CI: $0.64-2.05$, respectively). Only one genome-wide linkage scan ${ }^{60}$ provided evidence of linkage at the chromosomal region 7q36, which harbors the eNOS gene. None of the genome-wide association studies ${ }^{69,70}$ showed association with eNOS gene polymorphisms.

\section{DISCUSSION}

Why some diabetics develop nephropathy, whereas others do not, despite having a long-term hyperglycemia, ${ }^{17}$ remains an unresolved question. Because known environmental factors do not fully explain this, researchers have sought the answer at the genetic background of the host. Polymorphisms in the eNOS gene that lead to decreased NO expression have been implicated with DN. The mechanism responsible for the potential association between eNOS polymorphisms and risk of DN is not known yet. However, variants of eNOS gene may cause defective NO synthesis and decreased NO levels, enhancing the susceptibility to glomerular disease and deteriorating the renal function. ${ }^{6,42}$ Therefore, this metabolic pathway of diabetes may be involved in renal complications of diabetes. To partly address the main limitation of the published candidate-gene association studies - the low sample sizes in single studies, because usually thousands of individuals are needed to provide convincing information - a meta-analysis of all eligible studies was performed.

This meta-analysis examined the eNOS G894T, 4a/b, and T786C polymorphisms and their relationship to susceptibility for DN. Its strength was based on the accumulation of published data giving greater information to detect significant differences. In total, the meta-analysis involved 11 studies for DN and 13 studies for DSN, which provided 5462/4538 cases/controls and 


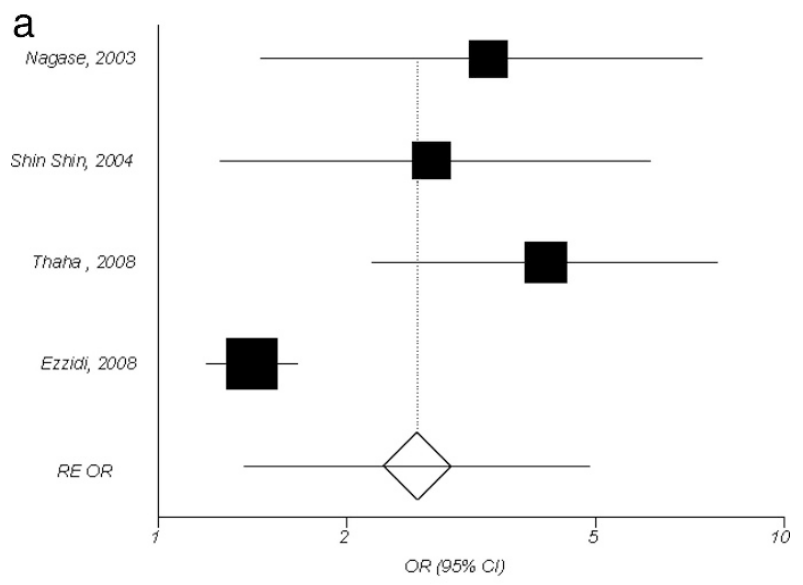

b

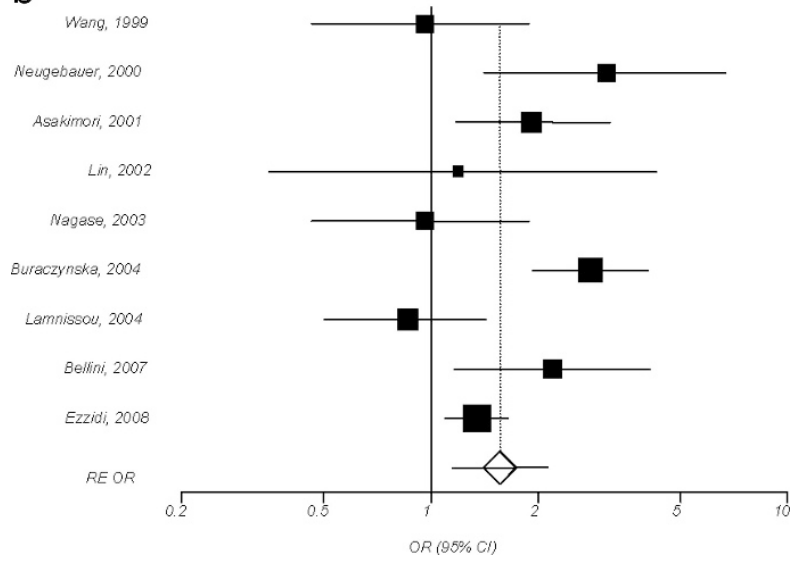

Fig. 3. Random effects (RE) odds ratio (OR) estimates with the corresponding $95 \%$ confidence interval $(\mathrm{Cl})$ for the allele contrast (a) G894T allele T and (b) 4b/a allele b and the risk of DSN. The OR estimate of each study is marked with a solid black square. The size of the square represents the weight that the corresponding study exerts in the metaanalysis. The Cls of pooled estimates are displayed as a horizontal line through the diamond; this line might be contained within the diamond if the confidence interval is narrow. The horizontal axis is plotted on a log scale.

1939/3508 cases/controls, respectively. Non-English, nonindexed, and nonpublished studies literature were not reviewed, thus introducing some bias. ${ }^{72}$ Studies demonstrating significant results are more likely to be published, especially in Englishlanguage indexed journals, as opposed to studies presenting negative findings, which are more likely to be published in a local journal, often nonindexed. ${ }^{73}$ In this study, the effect of allele frequency and the effects of the dominant, recessive, and additive models were estimated. In addition, the consistency of genetic effects across populations from different ethnicities was investigated. ${ }^{26}$ Subgroup analysis by diabetes type, and sensitivity for studies not in HWE, was performed. However, in main analyses and subgroup analyses, the testing of associations was based on different amount of information in each instance. Therefore, any comparisons between the effect sizes should be interpreted with caution.

For DN, the main analysis showed a marginal association only for $4 \mathrm{~b} / \mathrm{a}$ polymorphism; however, there was no overall



Fig. 4. Cumulative meta-analysis for diabetic nephropathy (DN) and diabetes leading to nephropathy (DSN): the random effects pooled odds ratio (OR) with the corresponding $95 \%$ confidence interval $(\mathrm{Cl})$ at the end of each year-information step is shown.

effect stratified by subgroup. The G894T and T786C polymorphisms produced marginal or no associations, except for T2DM in G894T. Genetic effects were consistent for whites and East Asians. The overall lack of (or weak) association between G894T, 4b/a, and T786C polymorphisms and DN might be due to other unidentified functional mutations that exist in the eNOS gene that affect the susceptibility to DN. It has been reported that polymorphisms in LD and their interactions within haplotypes can be the major determinants of disease susceptibility instead of the individual polymorphisms. ${ }^{10,74}$ Individual eNOS genotypes might not be reliable markers of risk for developing $\mathrm{DN}$; consequently, a meta-analysis of haplotypes could provide more reliable information. The family-based and genome-wide studies did not provide evidence that supports implication of eNOS in DN, with the exception of one genome-wide linkage scan.

For DSN, the main and subgroup analysis in East Asians produced significant results for G894T and 4b/a. The subgroup analyses for T2DM showed significant association for G894T and nonsignificant for $4 \mathrm{~b} / \mathrm{a}$; however, these findings were based on a very small number of studies, and the results should be interpreted with caution. Sensitivity analysis for HWE in G894T did not alter the pattern of results. There is no differential magnitude of effect in large versus small studies. A major finding of this meta-analysis was that associations differ for DSN and DN. This implies that eNOS gene may also indicate susceptibility to diabetes. It has been shown that eNOS polymorphisms are implicated in insulin resistance and T2DM ${ }^{75,76}$; however, replication studies providing strong evidence of this association do not exist.

The meta-analysis included only one study with a case group consisting of patients with persistent macroalbuminuria or microalbuminuria, ${ }^{40}$ but the proportion of patients with microalbuminuria was very small (18\%); thus, the pooled estimated risk of $\mathrm{DN}$ is not underestimated. The different methods used in the studies to determine urinary albumin excretion and the respective cutoffs to define macroalbuminuria or microalbuminuria were equivalent and clinically validated. ${ }^{14}$

In the meta-analysis, only the unadjusted pooled ORs were calculated, because data for possible confounding factors that 
influence the estimates of associations (e.g., age, sex, and lifestyle) were not provided. Sampling variability and stratification in genetic association studies could be a possible confounding factor on the role of genetic markers. The strict selection criteria ensure a clear case and control definition for meta-analysis, because when the possibility for a case to be considered as a control is minimized, then the estimation of risk is unbiased. The cases and controls of each study were well defined with similar inclusion criteria, although they unavoidably cover a wide spectrum of disease, in terms of duration, demographics, and other clinical manifestations. The existence of diversity of these factors across studies may result to the presence of heterogeneity. In addition, the risk effect may depend on the interaction with other risk factors: smoking, alcohol consumption, exercise, control of diabetes, and body mass index, all of which modulate the development of DN. ${ }^{77,78}$ Prevalence of DN depends on age, and it is maximized in elderly individuals. Thus, the absence of DN in young diabetics does not exclude the possibility of developing DN later. In many studies, younger individuals were frequently included as controls. Therefore, if a control group may include cases that are still at risk for developing DN, then there is a fundamental risk of bias in these studies.

The retrospective design of studies included might have introduced survival-related bias. If a genetic variant not only increases the risk of DN but also influences survival, it is possible that risk-allele carriers will have advanced disease and die prematurely. Because DN is a disease with dismal prognosis, carriers of the risk genotype will be underrepresented at the time of enrolment in a case-control study. Prospective cohort studies of diabetic patients being followed up for the development of DN could address this issue.

In conclusion, this study supported lack of association between eNOS polymorphisms and DN and strong association among eNOS G894T, eNOS 4b/a, and DSN. The results of this meta-analysis regarding DN should be interpreted with some degree of caution, because the numbers of studies and participants were relatively small. However, $\mathrm{DN}$ is a complex disease with multifactorial etiology. Therefore, the contributing pathogenetic role of lifestyle factors and dietary intake should also be considered. The existence of gene-environment interactions may explain the discrepancy of results of individual genetic association studies, and therefore candidate-gene and genomewide $^{25}$ association studies that investigate gene-environment interactions ${ }^{79}$ might further elucidate the genetics of $\mathrm{DN}$.

\section{ACKNOWLEDGMENTS}

The authors thank Dr. George Kitsios for comments and discussion.

\section{REFERENCES}

1. Moncada S, Higgs EA. The discovery of nitric oxide and its role in vascular biology. Br J Pharmacol 2006;147(suppl 1):S193-S201.

2. Wang Y, Kikuchi S, Suzuki H, Nagase S, Koyama A. Endothelial nitric oxide synthase gene polymorphism in intron 4 affects the progression of renal failure in non-diabetic renal diseases. Nephrol Dial Transplant 1999; 14:2898-2902.

3. Noiri E, Satoh H, Taguchi J, et al. Association of eNOS Glu298Asp polymorphism with end-stage renal disease. Hypertension 2002;40:535-540.

4. Zanchi A, Moczulski DK, Hanna LS, Wantman M, Warram JH, Krolewski AS. Risk of advanced diabetic nephropathy in type 1 diabetes is associated with endothelial nitric oxide synthase gene polymorphism. Kidney Int 2000; 57:405-413

5. Ezzidi I, Mtiraoui N, Mohamed MB, Mahjoub T, Kacem M, Almawi WY. Association of endothelial nitric oxide synthase Glu298Asp, 4b/a, and $-786 \mathrm{~T}>\mathrm{C}$ gene variants with diabetic nephropathy. J Diabetes Complications 2008;22:331-338.

6. Ahluwalia TS, Ahuja M, Rai TS, et al. Endothelial nitric oxide synthase gene haplotypes and diabetic nephropathy among Asian Indians. Mol Cell Biochem 2008;314:9-17

7. Yoshimura M, Yasue H, Nakayama M, et al. A missense Glu298Asp variant in the endothelial nitric oxide synthase gene is associated with coronary spasm in the Japanese. Hum Genet 1998;103:65-69.

8. Nakayama $M$, Yasue $H$, Yoshimura $M$, et al. T-786 $->C$ mutation in the 5 '-flanking region of the endothelial nitric oxide synthase gene is associated with coronary spasm. Circulation 1999;99:2864-2870.

9. Wang XL, Wang J. Endothelial nitric oxide synthase gene sequence variations and vascular disease. Mol Genet Metab 2000;70:241-251.

10. Zintzaras E, Kitsios G, Stefanidis I. Endothelial NO synthase gene polymorphisms and hypertension: a meta-analysis. Hypertension 2006;48:700710 .

11. Thomas GD, Zhang W, Victor RG. Nitric oxide deficiency as a cause of clinical hypertension: promising new drug targets for refractory hypertension. JAMA 2001;285:2055-2057.

12. Wang XL, Sim AS, Badenhop RF, McCredie RM, Wilcken DE. A smokingdependent risk of coronary artery disease associated with a polymorphism of the endothelial nitric oxide synthase gene. Nat Med 1996;2:41-45.

13. Asakimori Y, Yorioka N, Taniguchi Y, et al. T(-786)- $>$ C polymorphism of the endothelial nitric oxide synthase gene influences the progression of renal disease. Nephron 2002;91:747-751.

14. Gross JL, de Azevedo MJ, Silveiro SP, Canani LH, Caramori ML, Zelmanovitz T. Diabetic nephropathy: diagnosis, prevention, and treatment. Diabetes Care 2005;28:164-176.

15. Adler AI, Stevens RJ, Manley SE, Bilous RW, Cull CA, Holman RR. Development and progression of nephropathy in type 2 diabetes: the United Kingdom Prospective Diabetes Study (UKPDS 64). Kidney Int 2003;63: 225-232.

16. Newman DJ, Mattock MB, Dawnay AB, et al. Systematic review on urine albumin testing for early detection of diabetic complications. Health Technol Assess 2005;9:iii-vi, xiii-163.

17. Krolewski AS, Warram JH, Christlieb AR, Busick EJ, Kahn CR. The changing natural history of nephropathy in type I diabetes. Am J Med 1985;78:785-794

18. Shpichinetsky V, Raz I, Friedlander Y, et al. The association between two common mutations C677T and A1298C in human methylenetetrahydrofolate reductase gene and the risk for diabetic nephropathy in type II diabetic patients. J Nutr 2000;130:2493-2497.

19. Borch-Johnsen K, Norgaard K, Hommel E, et al. Is diabetic nephropathy an inherited complication? Kidney Int 1992;41:719-722.

20. Quinn M, Angelico MC, Warram JH, Krolewski AS. Familial factors determine the development of diabetic nephropathy in patients with IDDM. Diabetologia 1996;39:940-945.

21. Strojek K, Grzeszczak W, Morawin E, et al. Nephropathy of type II diabetes: evidence for hereditary factors? Kidney Int 1997;51:1602-1607.

22. Zintzaras E, Stefanidis I. Association between the GLUT1 gene polymorphism and the risk of diabetic nephropathy: a meta-analysis. J Hum Genet 2005;50:84-91.

23. Zintzaras E, Uhlig K, Koukoulis GN, Papathanasiou AA, Stefanidis I. Methylenetetrahydrofolate reductase gene polymorphism as a risk factor for diabetic nephropathy: a meta-analysis. J Hum Genet 2007;52:881-890.

24. Freedman BI, Bostrom M, Daeihagh P, Bowden DW. Genetic factors in diabetic nephropathy. Clin J Am Soc Nephrol 2007;2:1306-1316.

25. Zintzaras E, Lau J. Synthesis of genetic association studies for pertinent gene-disease associations requires appropriate methodological and statistical approaches. J Clin Epidemiol 2008;61:634-645

26. Zintzaras E, Lau J. Trends in meta-analysis of genetic association studies. J Hum Genet 2008;53:1-9.

27. Trikalinos TA, Salanti G, Zintzaras E, Ioannidis JP. Meta-analysis methods. Adv Genet 2008;60:311-334.

28. Lau J, Antman EM, Jimenez-Silva J, Kupelnick B, Mosteller F, Chalmers TC. Cumulative meta-analysis of therapeutic trials for myocardial infarction. N Engl J Med 1992;327:248-254.

29. Frosst P, Blom HJ, Milos R, et al. A candidate genetic risk factor for vascular disease: a common mutation in methylenetetrahydrofolate reductase. Nat Genet 1995;10:111-113.

30. Minelli C, Thompson JR, Abrams KR, Thakkinstian A, Attia J. The choice of a genetic model in the meta-analysis of molecular association studies. Int $J$ Epidemiol 2005;34:1319-1328.

31. Falconer DS. Introduction to quantitative genetics. 3rd ed. New York, NY: Longman Scientific \& Technical, 1989.

32. Cochran W. The combination of estimates from different experiments. Biometrics 1954;10:101-129.

33. Higgins JP, Thompson SG. Quantifying heterogeneity in a meta-analysis. Stat Med 2002;21:1539-1558.

34. DerSimonian R, Laird N. Meta-analysis in clinical trials. Control Clin Trials 1986;7:177-188

35. Harbord RM, Egger M, Sterne JA. A modified test for small-study effects in meta-analyses of controlled trials with binary endpoints. Stat Med 2006;25: 3443-3457. 
36. Weir B. Genetic data analysis ii: methods for discrete population genetic data. Sunderland, MA: Sinauer Associates, 1996.

37. Zintzaras E, Hadjigeorgiou GM. The role of G196A polymorphism in the brain-derived neurotrophic factor gene in the cause of Parkinson's disease: a meta-analysis. J Hum Genet 2005;50:560-566.

38. Thaha M, Pranawa, Yogiantoro M, et al. Association of endothelial nitric oxide synthase Glu298Asp polymorphism with end-stage renal disease. Clin Nephrol 2008;70:144-154.

39. Bellini MH, Figueira MN, Piccoli MF, et al. Association of endothelial nitric oxide synthase gene intron 4 polymorphism with end-stage renal disease. Nephrology (Carlton) 2007;12:289-293.

40. Mollsten A, Wessman M, Svensson M, et al. Glu298Asp and NOS4ab polymorphisms in diabetic nephropathy. Ann Med 2006;38:522-528.

41. Lamnissou K, Zirogiannis P, Trygonis S, et al. Evidence for association of endothelial cell nitric oxide synthase gene polymorphism with earlier progression to end-stage renal disease in a cohort of Hellens from Greece and Cyprus. Genet Test 2004;8:319-324.

42. Shin Shin Y, Baek SH, Chang KY, et al. Relations between eNOS Glu298Asp polymorphism and progression of diabetic nephropathy. Diabetes Res Clin Pract 2004;65:257-265.

43. Buraczynska M, Ksiazek P, Zaluska W, Nowicka T, Ksiazek A. Endothelial nitric oxide synthase gene intron 4 polymorphism in patients with end-stage renal disease. Nephrol Dial Transplant 2004;19:2302-2306.

44. Nagase S, Suzuki H, Wang Y, et al. Association of ecNOS gene polymorphisms with end stage renal diseases. Mol Cell Biochem 2003:244:113-118.

45. Rippin JD, Patel A, Belyaev ND, Gill GV, Barnett AH, Bain SC. Nitric oxide synthase gene polymorphisms and diabetic nephropathy. Diabetologia 2003;46:426-428.

46. Shimizu T, Onuma T, Kawamori R, Makita Y, Tomino Y. Endothelial nitric oxide synthase gene and the development of diabetic nephropathy. Diabetes Res Clin Pract 2002;58:179-185.

47. Lin S, Qu H, Qiu M. Allele A in intron 4 of ecNOS gene will not increase the risk of diabetic nephropathy in type 2 diabetes of Chinese population. Nephron 2002;91:768.

48. Asakimori Y, Yorioka N, Yamamoto I, et al. Endothelial nitric oxide synthase intron 4 polymorphism influences the progression of renal disease. Nephron 2001;89:219-223.

49. Taniwaki H, Ishimura $\mathrm{E}$, Matsumoto $\mathrm{N}$, Emoto $\mathrm{M}$, Inaba $\mathrm{M}$, Nishizawa $\mathrm{Y}$. Relations between $A C E$ gene and ecNOS gene polymorphisms and resistive index in type 2 diabetic patients with nephropathy. Diabetes Care 2001;24: 1653-1660.

50. Neugebauer S, Baba T, Watanabe T. Association of the nitric oxide synthase gene polymorphism with an increased risk for progression to diabetic nephropathy in type 2 diabetes. Diabetes 2000;49:500-503.

51. Fujita H, Narita T, Meguro H, et al. Lack of association between an ecNOS gene polymorphism and diabetic nephropathy in type 2 diabetic patients with proliferative diabetic retinopathy. Horm Metab Res 2000;32:80-83.

52. Degen B, Schmidt S, Ritz E. A polymorphism in the gene for the endothelial nitric oxide synthase and diabetic nephropathy. Nephrol Dial Transplant 2001; $16: 185$

53. Cai H, Wang X, Colagiuri S, Wilcken DE. A common Glu298->Asp $(894 \mathrm{G}->\mathrm{T})$ mutation at exon 7 of the endothelial nitric oxide synthase gene and vascular complications in type 2 diabetes. Diabetes Care 1998;21:21952196.

54. Suzuki H, Nagase S, Kikuchi S, Wang Y, Koyama A. Association of a missense Glu298Asp mutation of the endothelial nitric oxide synthase gene with end stage renal disease. Clin Chem 2000;46:1858-1860.

55. Ksiazek P, Wojewoda P, Muc K, Buraczynska M. Endothelial nitric oxide synthase gene intron 4 polymorphism in type 2 diabetes mellitus. Mol Diagn 2003; 7:119-123.

56. Ewens KG, George RA, Sharma K, Ziyadeh FN, Spielman RS. Assessment of 115 candidate genes for diabetic nephropathy by transmission/disequilibrium test. Diabetes 2005;54:3305-3318.

57. Rogus JJ, Poznik GD, Pezzolesi MG, et al. High-density single nucleotide polymorphism genome-wide linkage scan for susceptibility genes for diabetic nephropathy in type 1 diabetes: discordant sibpair approach. Diabetes 2008;57:2519-2526.
58. Freedman BI, Bowden DW, Rich SS, et al. A genome scan for all-cause end-stage renal disease in African Americans. Nephrol Dial Transplant 2005;20:712-718

59. Freedman BI, Bowden DW, Rich SS, et al. Genome-wide linkage scans for renal function and albuminuria in type 2 diabetes mellitus: the Diabetes Heart Study. Diabet Med 2008;25:268-276.

60. Krolewski AS, Poznik GD, Placha G, et al. A genome-wide linkage scan for genes controlling variation in urinary albumin excretion in type II diabetes. Kidney Int 2006;69:129-136.

61. Osterholm AM, He B, Pitkaniemi J, et al. Genome-wide scan for type 1 diabetic nephropathy in the Finnish population reveals suggestive linkage to a single locus on chromosome 3q. Kidney Int 2007;71:140-145.

62. Chen G, Adeyemo AA, Zhou J, et al. A genome-wide search for linkage to renal function phenotypes in West Africans with type 2 diabetes. Am J Kidney Dis 2007;49:394-400.

63. Bowden DW, Colicigno CJ, Langefeld CD, et al. A genome scan for diabetic nephropathy in African Americans. Kidney Int 2004;66:1517-1526.

64. Imperatore G, Hanson RL, Pettitt DJ, Kobes S, Bennett PH, Knowler WC. Sib-pair linkage analysis for susceptibility genes for microvascular complications among Pima Indians with type 2 diabetes. Pima Diabetes Genes Group. Diabetes 1998;47:821-830.

65. Iyengar SK, Abboud HE, Goddard KA, et al Genome-wide scans for diabetic nephropathy and albuminuria in multiethnic populations: the Family Investigation of Nephropathy and Diabetes (FIND). Diabetes 2007;56:15771585 .

66. Moczulski DK, Rogus JJ, Antonellis A, Warram JH, Krolewski AS. Major susceptibility locus for nephropathy in type 1 diabetes on chromosome $3 q$ : results of novel discordant sib-pair analysis. Diabetes 1998;47:1164-1169.

67. Vardarli I, Baier LJ, Hanson RL, et al. Gene for susceptibility to diabetic nephropathy in type 2 diabetes maps to 18q22.3-23. Kidney Int 2002;62: 2176-2183

68. Placha G, Poznik GD, Dunn J, et al. A genome-wide linkage scan for genes controlling variation in renal function estimated by serum cystatin $\mathrm{C}$ levels in extended families with type 2 diabetes. Diabetes 2006;55:3358-3365.

69. Pezzolesi MG, Poznik GD, Mychaleckyj JC, et al. Genome-wide association scan for diabetic nephropathy susceptibility genes in type 1 diabetes. Diabetes 2009;58:1403-1410.

70. Maeda S, Osawa N, Hayashi T, Tsukada S, Kobayashi M, Kikkawa R. Genetic variations associated with diabetic nephropathy and type II diabetes in a Japanese population. Kidney Int Suppl 2007:S43-S48.

71. Tanaka N, Babazono T, Saito S, et al. Association of solute carrier family 12 (sodium/chloride) member 3 with diabetic nephropathy, identified by genome-wide analyses of single nucleotide polymorphisms. Diabetes 2003;52: 2848-2853.

72. Egger M, Zellweger-Zahner T, Schneider M, Junker C, Lengeler C, Antes G. Language bias in randomised controlled trials published in English and German. Lancet 1997;350:326-329.

73. Zintzaras E, Kaditis AG. Sleep-disordered breathing and blood pressure in children: a meta-analysis. Arch Pediatr Adolesc Med 2007;161:172-178.

74. Zintzaras E, Koufakis T, Ziakas PD, Rodopoulou P, Giannouli S, Voulgarelis M. A meta-analysis of genotypes and haplotypes of methylenetetrahydrofolate reductase gene polymorphisms in acute lymphoblastic leukemia. Eur J Epidemiol 2006;21:501-510.

75. Monti LD, Barlassina C, Citterio L, et al. Endothelial nitric oxide synthase polymorphisms are associated with type 2 diabetes and the insulin resistance syndrome. Diabetes 2003;52:1270-1275.

76. Ohtoshi K, Yamasaki Y, Gorogawa S, et al. Association of (-)786T-C mutation of endothelial nitric oxide synthase gene with insulin resistance. Diabetologia 2002;45:1594-1601.

77. Passaro A, Calzoni F, Volpato S, et al. Effect of metabolic control on homocysteine levels in type 2 diabetic patients: a 3-year follow-up. J Intern Med 2003;254:264-271.

78. Ma J, Stampfer MJ, Giovannucci E, et al. Methylenetetrahydrofolate reductase polymorphism, dietary interactions, and risk of colorectal cancer. Cancer Res 1997;57:1098-1102.

79. Clayton D, McKeigue PM. Epidemiological methods for studying genes and environmental factors in complex diseases. Lancet 2001;358:1356-1360. 